\section{CALIBRATION AND VALIDATION OF SWMM MODEL IN A SUB CATCHMENT IN ELDORET TOWN, KENYA}

\author{
Rotich Abraham Metto ${ }^{a}$, Kiptum Clement Kiprotich ${ }^{\mathrm{a}^{*}}$, Kipkorir \\ Emmanuel Chessum ${ }^{\text {b }}$
}

aschool of Engineering, University of Eldoret, Kenya



Article history

Received

19 April 2020

Received in revised form 29 November 2020

Accepted

5 December 2020

Published online

31 March 2021

\section{*Corresponding author} ckiptum@uoeld.ac.ke

\begin{abstract}
Flooding in Eldoret town has been occurring during heavy downpours resulting in loss of property, live and interruption of transportation systems. This study aimed at determining the catchment characteristics in Eldoret town for the calibration and validation of SWMM5 model. This model was developed by US Environmental Protection Agency. The model has been evolving from Version 1 in 1971 to Version 5 of 2005 called SWMM5. It can simulate runoff quantity in any given catchment. Rainfall was measured using rain gauge while discharge was measured using current meter. Digital Elevation Model of the study area was also obtained. The results showed that the catchment drained an area of approximately 696.5 hectares with a total of 23 sub catchments. The average slope was found to be $2.57 \%$ and the mean average imperviousness was $25.72 \%$. The drain base flow was found to be $0.002 \mathrm{~m} 3 / \mathrm{s}$. However, during prolonged rainfall, the discharge increased up to $32.4 \mathrm{~m} 3 / \mathrm{s}$. The maximum rainfall observed during the study period was $32.4 \mathrm{~mm}$ which resulted in the maximum average discharge of $0.131 \mathrm{~m} 3 / \mathrm{s}$ and resulted in overflow in the drain. Calibrated model had $\mathrm{N}$ Imperv of 0.45 , Dstore-Imperv of 2.5 and Dstore-Perv of 8 . ISE values of 1.9 and 1.4 were observed for calibration and validation, respectively. NSE values of 0.97 and 0.99 were observed for calibration and validation, respectively. This meant that model excellently simulated rainfall-discharge relationship in the study area and can be used for final design by the Eldoret town engineers. Future study is required to calibrate the model based on more measurements of rainfall and their discharges in the catchment.
\end{abstract}

Keywords: Calibration, Discharge, Eldoret, Flooding, SWMM5 model

(c) 2021 Penerbit UTM Press. All rights reserved

\subsection{INTRODUCTION}

Floods occur because of the rapid accumulation and release of runoff waters from upstream to downstream (Ouma and Tateishi, 2014). Urban stream flow is a subject of great concern worldwide (Booth et al., 2014). Some regions of the world have benefited from well managed urban stream flows while others have had problems associated with storm waters which lead to serious social economic and ecological impacts (Walsh et al., 2005). Floods occur in rural and urban areas in Kenya. Eldoret town, experiences floods during the rainy season. The main causes of the observed flooding phenomena in Eldoret are characteristically due to unplanned urban development, drainage clogging and precipitation intensities among other hydrological factors.

The situation is aggravated further by increase in population growth compounded by poorly planned land-use practices which have impacted negatively on the catchment's structural and natural ecological stability over the years. This is more pronounced in one of the main tributary to Sosiani River in Eldoret town. The stream was initially covered with reeds but now it is a drain. The area that used to be swampy has been developed leading to the increase of impervious surface with the attendant risk of flooding the drain. When flooding occurs, loss of property and lives can occur as witnessed in the study area (Bwisa, 2014).

As developments take place, the amount of impervious surface will increase and discharge into the drain will increase and if it is going to flood it will damage many houses and other properties next to the Trokadero Bus Stage. There is need to develop sustainable cities that guarantee safety of people and property from disasters like storms and resulting runoff. This calls for mitigation measures to control floods in the urban areas which can be done using modeling techniques like Storm Water Management Model (SWMM) which has been tested for small towns and is used worldwide (Kourtis et al., 2017, 
Niyonkuru et al., 2018). This model was developed by US Environmental Protection Agency. The model has been evolving from Version 1 in 1971 to Version 5 of 2005 called SWMM5. SWMM5 can be used for a single event or long-term simulation of runoff quantity primarily from urban areas. The model uses a 1-D approach for dynamic wave routing producing the most theoretically accurate results (Niazi et al., 2017).

Rainfall-runoff modeling informs flood control prevention in planning for sustainable and secure towns in regard to flood damages, through flood prediction (Blöschl et al., 2008), formulation of stormwater management strategy and drainage system design (Crobeddu et al., 2007). To model hydrological processes in SWMM5 model, sub-catchments are divided into impervious and pervious areas and expressed as a percentage of the total drain area. Losses in impervious areas are only due to depression storage, while in pervious areas losses occur due to infiltration (Cambez et al., 2008). Since SWMM is in use internationally, it is good practice to test in every corner of the globe to inform future versions improvement of the model by addressing model inefficiencies as argued by Pretorius et al., 2013.

Therefore, there was need to determine rainfall intensities and percentage of imperviousness that resulted in flooding of the Eldoret drain with a view of calibrating and validating SWMM5 model for rainfall-runoff simulation in Eldoret town stream which has not been done. Validated model will assist the town planning department to control development.

\subsection{METHODOLOGY}

\subsection{Study Area}

This study was conducted in Eldoret town (Figure 1) which lies within latitude $0.26^{\circ} 3^{\prime} \mathrm{N}-0.35^{\circ} 34^{\prime} \mathrm{N}$ and longitude $35.12^{\circ} 21^{\prime} \mathrm{E}$ - 35.20³1' E.

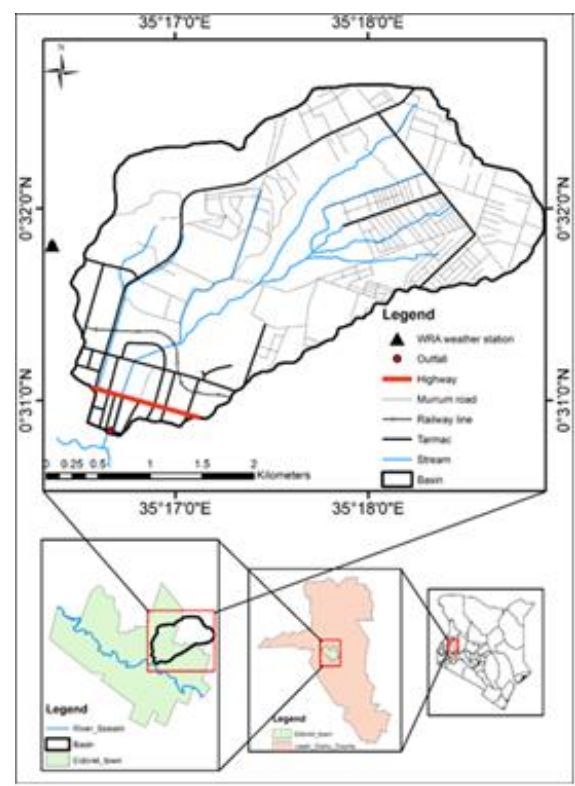

Figure 1: Map of the study area

The study area experiences two rainy seasons with average rainfall ranging from $900 \mathrm{~mm}$ to $1,200 \mathrm{~mm}$ per annum and average temperature range between $8.40 \mathrm{C}$ and $270 \mathrm{C}$ (Kemboi et al., 2018). Rocks in the study area are volcanic. Soils are primarily red to strong-brown friable clays with laterite horizon and gleysols that do not drain easily (Kiptum and Ndambuki, 2012).

\subsection{Modeling Inputs}

\subsubsection{Areo}

A digital Elevation model (DEM) for 2014 was downloaded from earth explorer 2019 from United States Geological Survey's Earth Explorer site (http://earthexplorer.usgs.gov/) defined by attributes: Entity ID (SRTM1N00E035V3); Date of acquisition was 11.02.2000; Date of publication was 23.09.2014. This is an open source data download service. The digital elevation model had a resolution of 1-ARC SEC $(30 \mathrm{~m} \times 30 \mathrm{~m})$ in ASCII Grid format.

The study sub catchment was obtained through DEM delineation in ArcGIS 10.2.2 toolbox under hydrology. The gauging point at Bandaptai in Eldoret was selected as the outfall of the catchment. This process resulted in the definition of the basin (study sub catchment) that drains its water through the outfall of the sub catchment (gauging point). Area computation tool was then used in ArcGIS 10.2.2 environment to determine the area of the study sub catchment.

For detailed SWMM model structure, the study sub catchment had to be further sub divided into sub basins. Subdivisions were performed in ArcGIS by introducing additional pour points along the streams within a catchment based on the stormwater system layout and flow accumulation grid. Area of each sub basin was also determined.Width of each sub basin was estimated by dividing the area of a basin by its longest flow path.

\subsubsection{Slope}

Study sub catchment polygon which had been obtained during delineation to determine the area, was used to clip DEM for the sub catchment. The downloaded area of interest DEM was loaded as input feature, a process which resulted in obtaining a DEM for the study sub catchment. Slope was computed in percentage using surface tool under spatial analyst extension in Arc map 10.2.2 Software. Slope in percentage was then classified into three classes.

\subsubsection{Percentage Imperviousness}

Determination of percentage imperviousness for each sub catchment was done using the grid method. A shape file of the study area sub catchment indicating the sub basins was loaded onto Google Earth software; which was able to provide a 2019 April image of the area of interest. The sub basins were marked as S1 to S23. Each sub basin was zoomed in to fit the computer screen and printed upon which $1 \mathrm{~cm}$ grids were drawn over and the grid method applied through close observation and calculation to obtain the percentage impervious area for each sub basin. Impervious areas include developed areas which could allow very low water infiltration to take place. Weighted percentage proportion of each sub basin as expressed in respect to its size and proportion to the entire area was determined. These percentages were then summed up to come 
up with the percentage imperviousness of the entire study sub catchment.

\subsubsection{Rainfall and Outfall Discharge}

Rainfall was measured using the standard rain gauge and rainfall records were recorded every 30 minutes. The rain gauge was located $1 \mathrm{~km}$ away from the discharge point and the observed rainfall was assumed to be the total amount of rain occurring in the catchment. Discharge through the outfall of the study area was measured by application of current meter method. Discharges were recorded before the rainfall, during the rainfall ( 30 minutes) and one hour after the rainfall event. The average discharge per rainfall event was determined for use in modeling. A total of six events were measured.

\subsubsection{Flow System Layout Parameters}

Hydraulics tool was used to enter junction parameters which were obtained through study area DEM analysis and ground measurement. These included the invert elevation of the junction and its maximum depth. A total of 19 junctions were considered for modeling. The same tool allowed for input of conduit parameters which were also obtained through DEM analysis and measurement. Conduit dimensions which included depth, bottom with and top width were determined through measurement by a tape measure. Side slopes were determined through calculation.

\subsection{Calibration and Validation of SWMM5 Model}

Three events were used in calibration. Parameters that were used for calibration of the model in Eldoret were; Manning's roughness coefficient for impervious area (N-IMPERV), Manning's roughness coefficient for impervious area (N-PERV), Depth of depression storage on impervious area (DstoreImperv), Depth of depression storage on impervious area (D-
store-Perv). Three events were also used to validate the model after the calibration process.

\subsubsection{Model Efficiency}

Four measures of fitness used to test model efficiency were; Coefficient of Determination $\left(R^{2}\right)$, Nash-Sutcliffe Efficiency (NSE), Integral Square Error (ISE) and Root Mean Square Error (RMSE). The coefficient of determination $R^{2}$ is defined as the squared value of the coefficient of correlation while RMSE represents the sample standard deviation of the differences between simulated and observed values. NSE value of 0.5 to 1.0 means excellent calibrating rating (Pretorious et al., 2013). ISE has an excellent measure of goodness-of-fit between observed and simulated hydrographs (Shamsi and Koran, 2017).

\subsection{RESULTS AND DISCUSSION}

\subsection{Catchment Characteristics}

The total area of sub catchment modelled was 696.5 hectares. This area was less than $1 \%$ of 166,130 hectares modeled by Niyonkuru et al., 2018. This showed that the model is robust and can work for both small and large catchments. Sub-division of the catchment resulted in 23 sub basins that formed the drainage of the study area. The size of each sub basin, slope and width are shown in Table 1 . Figure 2 indicates the sub basins, junctions and conduits within the study sub catchment.

The northern part of the study sub catchment consists of medium residential use while commercial buildings which are closely packed are found in the southern part of the sub catchment. The sub basin size averaged a value of 30.3 ha with the largest sub basin (S3) covering an area of 64.7 ha and the smallest (S23) being 3.9 ha.

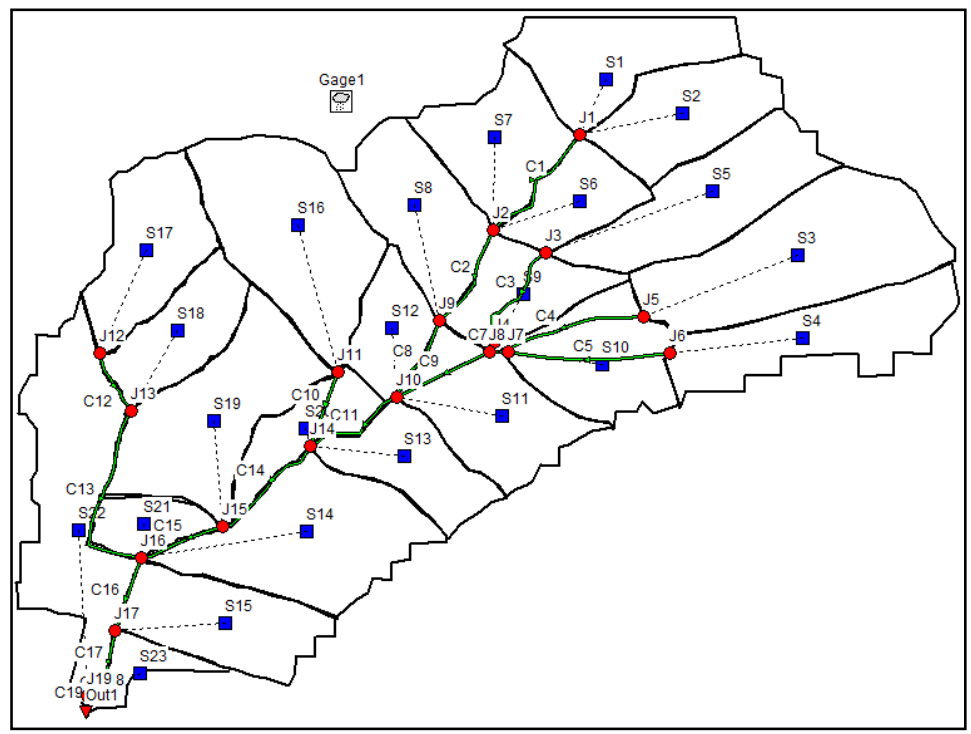

Figure 2 Sub basins, Channels, Junctions and gage station. 
Table 1 Sub basins attributes

\begin{tabular}{|c|c|c|c|c|}
\hline Sub Basin & Area (ha) & Width (m) & \% Imperviousness & Average\% Slope \\
\hline S1 & 27.6 & 262 & 38 & 1.8 \\
\hline S2 & 28.2 & 265 & 23 & 1.8 \\
\hline S3 & 64.7 & 402 & 39 & 2.1 \\
\hline S4 & 34.7 & 290 & 24 & 3.1 \\
\hline S5 & 37.4 & 305 & 23 & 2.2 \\
\hline S6 & 14.0 & 184 & 1 & 2.3 \\
\hline S7 & 26.2 & 255 & 18 & 2.7 \\
\hline S8 & 31.0 & 276 & 28 & 3.3 \\
\hline S9 & 17.5 & 205 & 18 & 1.9 \\
\hline S10 & 29.1 & 270 & 27 & 2.3 \\
\hline S11 & 42.2 & 326 & 14 & 2.2 \\
\hline S12 & 12.1 & 174 & 13 & 1.9 \\
\hline S13 & 19.6 & 221 & 13 & 2.4 \\
\hline S14 & 51.2 & 360 & 19 & 3.3 \\
\hline S15 & 29.1 & 270 & 29 & 3.8 \\
\hline S16 & 56.4 & 375 & 43 & 3.2 \\
\hline S17 & 29.1 & 270 & 11 & 3.3 \\
\hline S18 & 19.7 & 221 & 9 & 2.9 \\
\hline S19 & 49.0 & 350 & 23 & 2.4 \\
\hline S20 & 11.3 & 168 & 14 & 1.8 \\
\hline S21 & 5.2 & 114 & 15 & 2.2 \\
\hline S22 & 57.3 & 360 & 38 & 2.8 \\
\hline S23 & 3.9 & 100 & 68 & 3.3 \\
\hline
\end{tabular}

\subsubsection{Slope}

The maximum and minimum elevation above the sea level for the study area was found to be $2176 \mathrm{~m}$ and $2074 \mathrm{~m}$, respectively with mean elevation of $2150 \mathrm{~m}$. Slope in percentage was categorized into three classes as shown in Figure 3.

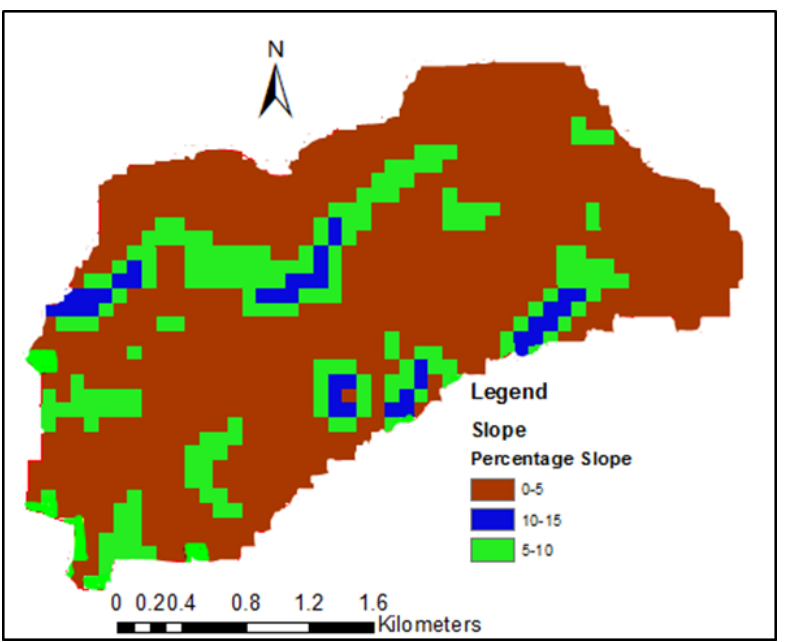

Figure 3: Slope Categories
The average slope used in SWMM5 model was $2.57 \%$, while maximum and minimum slope for the sub catchment was $0.2 \%$ and $14.3 \%$, respectively. There were three classes of slope namely; flat (0-5\%), gentle slope (5-10\%) and moderate slope (10-15\%). Flat area characterized the sub catchment with an area of 640.78 hectares equivalent to $92 \%$ of the total area, while gentle slope was $5 \%$ and moderate slope was $3 \%$ (20.89 ha). The slopes are similar to $5.3 \%$ to $37.1 \%$ used in US by Thompson et al., 2013.

\subsubsection{Percent Imperviousness}

Estimated impervious surface area was 169.5 hectares (25.72\%) of the total sub catchment area while 527 hectares (74.28\%) constituted the pervious surfaces (Figure 4). Sub basin S23 had the highest percentage imperviousness at $68 \%$ while sub basin S6 had the lowest percentage imperviousness at $1 \%$. Interestingly Sub basin 23 had the smallest area and had the highest imperviousness. S23 is in Eldoret town Central Business District. 




Figure 4: Impervious and Pervious areas

\subsubsection{Rainfall and Discharge through the Outfall}

The recorded rainfall and outfall discharges are presented in Table 2. The river base flow was found to be $0.002 \mathrm{~m}^{3} / \mathrm{s}$. However, during prolonged rainfall, the discharge increased up to $32.4 \mathrm{~m}^{3} / \mathrm{s}$. The highest recorded rainfall resulted in flooding while the rest didn't. The rainfall duration varied from thirty minutes to three hours. The time to peak was 30 minutes after rainfall.

Table 2: Recorded Rainfall and Discharge during the study

\begin{tabular}{|c|c|c|c|}
\hline Year & Date & Rainfall recorded ( $\mathrm{mm})$ & $\begin{array}{l}\text { Average Discharge at Catchment } \\
\text { Exit } \\
\left(\mathrm{m}^{3} / \mathrm{s}\right)\end{array}$ \\
\hline 2019 & 23 April, 2019 & 5.0 & 0.015 \\
\hline 2019 & 27 April, 2019 & 7.0 & 0.025 \\
\hline 2019 & $4^{\text {th }}$ July, 2019 & 8.0 & 0.034 \\
\hline 2019 & $11^{\text {th }}$ July, 2019 & 12.1 & 0.060 \\
\hline 2019 & $9^{\text {th }}$ August, 2019 & 32.4 & 0.131 \\
\hline
\end{tabular}

\subsubsection{Flow System Layout Parameters}

The conduits were open channels with trapezoidal shape. The dimensions of the channels were as follows: maximum depth $(1.5 \mathrm{~m})$, bottom width $(1.2 \mathrm{~m})$, top width $(1.5 \mathrm{~m})$ and side slopes of $1: 12$. The longest stream that drains the sub catchment measured 4500 meters. The channels, junctions and lengths are tabulated in Table 3. C5 and C7 were longest and shortest conduits, respectively. Roughness coefficient of 0.05 were for gravel or stony areas while roughness coefficient 0.02 were for channels lined with rubble masonry. 
Table 3: Junctions and Conduits data

\begin{tabular}{|c|c|c|c|c|c|c|}
\hline \multicolumn{4}{|c|}{ Nodes } & \multicolumn{3}{|c|}{ Links } \\
\hline Junction & Invert Elevation (m) & $\begin{array}{l}\text { Maximum } \\
\text { (m) }\end{array}$ & Depth & Conduit & Length (m) & Roughness Coefficient \\
\hline $\mathrm{J1}$ & 2160 & 1.5 & & $\mathrm{C} 1$ & 653 & 0.05 \\
\hline $\mathrm{J} 2$ & 2144 & 1.5 & & $\mathrm{C} 2$ & 541 & 0.05 \\
\hline $\mathrm{J} 3$ & 2144 & 1.5 & & C3 & 517 & 0.05 \\
\hline J4 & 2132 & 1.5 & & $\mathrm{C} 4$ & 713 & 0.05 \\
\hline $\mathrm{J} 5$ & 2148 & 1.5 & & C5 & 824 & 0.05 \\
\hline J6 & 2150 & 1.5 & & C6 & 89 & 0.05 \\
\hline$J 7$ & 2133 & 1.5 & & $\mathrm{C7}$ & 60 & 0.05 \\
\hline J8 & 2131 & 1.5 & & $\mathrm{C} 8$ & 447 & 0.05 \\
\hline 19 & 2131 & 1.5 & & C9 & 512 & 0.05 \\
\hline $\mathrm{J} 10$ & 2122 & 1.5 & & C10 & 394 & 0.05 \\
\hline J11 & 2127 & 1.5 & & C11 & 511 & 0.05 \\
\hline $\mathrm{J} 12$ & 2131 & 1.5 & & C12 & 326 & 0.05 \\
\hline $\mathrm{J} 13$ & 2118 & 1.5 & & C13 & 967 & 0.02 \\
\hline J14 & 2115 & 1.5 & & C14 & 607 & 0.05 \\
\hline $\mathrm{J} 15$ & 2103 & 1.5 & & C15 & 427 & 0.05 \\
\hline J16 & 2090 & 1.5 & & C16 & 381 & 0.05 \\
\hline J17 & 2081 & 1.5 & & C17 & 340 & 0.02 \\
\hline $\mathrm{J} 18$ & 2076 & 1.5 & & C18 & 47 & 0.02 \\
\hline J19 & 2075 & 1.5 & & C19 & 80 & 0.02 \\
\hline Out1 & 2074 & 1.5 & & & & \\
\hline
\end{tabular}

\subsection{Calibration and Validation of SWMM5 Model for Eldoret}

The adjusted values for calibration parameters are presented in Table 4. All the values were within the range indicated by the SWMM manual (Rossman, 2016). The value of $\mathrm{N}$-imperv was similar to that observed by Niyonkuru et al., 2018. This suggests that this value is the same for large and small catchments.

Table 4: Modeling Parameters

\begin{tabular}{llll}
\hline Parameter & Description & Initial Value & Calibrated Value \\
\hline N-Imperv & $\begin{array}{l}\text { Manning's roughness } \\
\text { coefficient for impervious } \\
\text { area }\end{array}$ & 0.01 & 0.015 \\
Nanning's roughness & 0.1 & 0.45 \\
& $\begin{array}{l}\text { coefficient for impervious } \\
\text { area } \\
\text { Depth of depression storage } \\
\text { Dstore-Imperv }\end{array}$ & 0.05 & 2.5 \\
on impervious area & & 8.0 \\
Dstore-Perv & $\begin{array}{l}\text { Depth of depression storage } \\
\text { on pervious area }\end{array}$ & 0.05 & \\
\hline
\end{tabular}

Table 5 Observed and simulated values for calibration and validation

\begin{tabular}{lll}
\hline & \multicolumn{1}{c}{ Calibration } \\
\hline Date & Observer Avg. Runoff & Simulated Avg. Runoff \\
\hline $27 / 4 / 2019$ & 0.025 & 0.024 \\
$23 / 4 / 2019$ & 0.015 & 0.015 \\
$4 / 7 / 2019$ & 0.034 & 0.033 \\
\hline \multicolumn{2}{l}{} \\
\hline $12 / 7 / 2019$ & \multicolumn{1}{c}{ Validation } \\
$9 / 8 / 2019$ & 0.074 & 0.076 \\
$11 / 7 / 2019$ & 0.131 & 0.132 \\
\hline
\end{tabular}


From Table 5, the model under-estimated the measured average discharges during calibration for two events. During validation, the model overestimated the discharges for two events and under estimated for one event.

Table 6: Measures of fitness with evaluated values for Calibration and Validation

\begin{tabular}{lll}
\hline Measure of Fitness & Calibrated & Validated \\
\hline Coefficient of Determination $\left(R^{2}\right)$ & 0.99 & 0.99 \\
Nash-Sutcliffe Efficiency (NSE) & 0.97 & 0.99 \\
Integral Square Error (ISE) & 1.91 & 1.41 \\
Root Mean Square Error (RMSE) & 0.0013 & 0.0022 \\
\hline
\end{tabular}

Calculated NSE and ISE values in Table 6 meant that the model could be used for planning, preliminary design and final design (Shamsi and Koran, 2017). NSE had a calibrated and validated value of 0.97 and 0.99 , respectively while ISE had a calibrated and validated value of 1.91 and 1.41 , respectively. The NSE values were agreeing with other researchers who reported the range of NSE of between 0.23 and 0.91(Niazi et al., 2017). In this study, $R^{2}$ had the same calibrated and validated value of 0.99 which meant the model can be used with high percentage of accuracy to run simulations and hence make predictions. RMSE had a value of $0.0013 \mathrm{~m}^{3} / \mathrm{s}$ calibrated and $0.0022 \mathrm{~m}^{3} / \mathrm{s}$ validated. These values were close to 0 meaning that observed and simulated values matched and hence the model was able to fit the data (Harris et al., 2010).

\subsection{CONCLUSION AND RECOMMENDATION}

The catchment was calibrated by having the following; N-Perv (0.45), Dstore-Imperv(2.5), Dstore-Perv (8.0). The model excellently simulated the average discharges in the study area and hence the possibility of using the model for final designs of drains in Eldoret town. The catchment was subdivided into 23 sub catchments with varying areas and levels of imperviousness. Catchment imperviousness ranged from $1 \%$ to $68 \%$. Average slope for the entire catchment was $2.57 \%$. The longest stream that drains the sub catchment measured about 4500 meters. Rainfall event of $32.4 \mathrm{~mm}$ resulted in the maximum average discharge of $0.131 \mathrm{~m}^{3} / \mathrm{s}$. The study recommends the widening of the drain to accommodate flows greater than $0.131 \mathrm{~m}^{3} / \mathrm{s}$. Another study can be done to calibrate the model by using different rainfall events and their resulting discharges.

\section{Acknowledgment}

The researchers would like to thank the Ministry of Education, Kenya, in collaboration with African Development Bank for financial support.

\section{References}

[1] Blöschl, G., Reszler, C., \&Komma, J. 2008. A spatially distributed flash flood forecasting model. Environmental Modelling\& Software, 23(4): 464-478.

[2] Booth, D. B., Kraseski, K. A., \& Rhett Jackson, C. 2014. Local-scale and watershed-scale determinants of summertime urban stream temperatures. Hydrological Processes, 28(4): 2427-2438.

[3] Bwisa, G. 2014. Huge losses as floods cause havoc in Eldoret. Kenya Daily Nation.

[4] Cambez, M. J., Pinho, J., \& David, L. M. 2008. Using SWMM 5 in the continuous modeling of stormwater hydraulics and quality. In 11th International Conference on Urban Drainage, Edinburgh, Scotland, UK. 1-10.

[5] Crobeddu, E., Bennis, S., \&Rhouzlane, S. 2007. Improved rational hydrograph method. Journal of Hydrology, 338(1-2): 63-72.

[6] Harris, P., Fotheringham, A. S., Crespo, R., \& Charlton, M. 2010. The use of geographically weighted regression for spatial prediction: an evaluation of models using simulated data sets. Mathematical Geosciences. 42(6): 657-680.

[7] U.S. Geological Survey, 2014, USGS EROS Data Center (http://earthexplorer.usgs.gov/) accessed on June, 21, 2019

[8] Kemboi, T. H., \&Jairus, K. N. 2018. Tour Guiding Performance Attributes and Tourist Satisfaction: Evidence from North Rift Tourist Region, Kenya. Journal of Hotel Management and Tourism Research 3: 8-23.

[9] Kiptum, C.K, and Ndambuki J.M. 2012. Well water contamination by pit latrines. A case study of Langas in Eldoret town. International Journal of Water Resources and Environmental Engineering. 4: 35-43.

[10] Kourtis, I. M., Kopsiaftis, G., Bellos, V., \& Tsihrintzis, V. A. 2017. Calibration and validation of SWMM model in two urban catchments in Athens, Greece. In International Conference on Environmental Science and Technology (CEST).

[11] Niazi, M., Nietch, C., Maghrebi, M. ASCE, A.M., Jackson, N., Bennett R.B., Tryby, Massoudieh, M. A. 2017. Storm Water Management Model: A review and gap analysis. Journal Sustainable Water Built Environment, 017, 3(2): 04017002

[12] Niyonkuru, P., Sang, J.K., Nyadawa, M.O., and Munyaneza, O. 2018 Calibration and Validation of EPA SWMM for Stormwater runoff modeling in Nyabugogo Cathment, Rwanda. Journal of Sustainable Research in Engineering. 4(4): 152-159.

[13] Ouma, Y. O., \&Tateishi, R. 2014. Urban flood vulnerability and risk mapping using integrated multi-parametric AHP and GIS: methodological overview and case study assessment. Water, 6(6) 1515-1545.

[14] Pretorius, H., James, W. and Smith, J. 2013. A strategy for Managing Deficieciences of SWMM Modelling for Large Undeveloped Semi-Arid Watersheds. Journal of Water Management Modelling 10.14796/JWMM.R246-01.

[15] Rossman, L. A. 2016. Storm water management model user's manual, version 5.0, 276. Cincinnati: National Risk Management Research 
Laboratory, Office of Research and Development, US Environmental Protection Agency.

[16] Shamsi, U. M. S., \& Koran, J. 2017. Continuous calibration. Journal of Water Management Modeling.

[17] Thompson, J.R., Wu, J.Y., Kolka, R.K., Franz, K.J. and Stewart, T.W. 2013. Using the Storm Water Management Model to Predict Urban Headwater Stream Hydrological Response to Climate. Hydrol. Earth System. Sci., 17: 4743-4758.
[18] Walsh, C. J., Roy, A. H., Feminella, J. W., Cottingham, P. D., Groffman, P. M., \& Morgan, R. P. 2005. The urban stream syndrome: current knowledge and the search for a cure. Journal of the North American Benthological Society, 24(3): 706-723. 